\title{
Dynamic Polyamide Networks via Amide-Imide Exchange
}

\author{
Yinjun Chen, Huiyi Zhang, Soumabrata Majumdar, Rolf A.T.M. van Benthem, Johan P. A. Heuts, * \\ and Rint P. Sijbesma*
}

Cite This: Macromolecules 2021, 54, 9703-9711

Read Online

ACCESS | Lلll Metrics \& More | 回 Article Recommendations | st Supporting Information

ABSTRACT: The diamide-imide equilibrium was successfully exploited for the synthesis of dynamic covalent polymer networks in which a dissociative bond exchange mechanism leads to high processibility at temperatures above $\approx 110^{\circ} \mathrm{C}$. Dynamic covalent networks bridge the gap between thermosets and thermoplastic polymers. At the operating temperature, when the network is fixed, dynamic covalent networks are elastic solids, while at high temperatures, chemical exchange reactions turn the network into a processible viscoelastic material. Upon heating a dissociative network, the viscosity may also decrease due to a shift of the chemical equilibrium; in such materials, the balance between processibility and excessive flow is important. In this study, a network is prepared that upon heating to above $\approx 110{ }^{\circ} \mathrm{C}$ dissociates to a significant extent due to a shift in the amide-imide equilibrium of a bisimide, pyromellitic diimide, in combination with poly(tetrahydrofuran) diamines. At room temperature, the

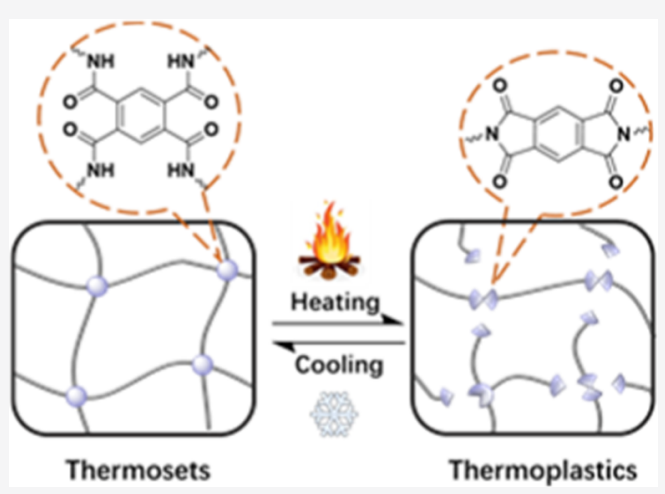
resulting materials are elastic rubbers with a tensile modulus of $2-10 \mathrm{MPa}$, and they become predominantly viscous above a temperature of approximately $110^{\circ} \mathrm{C}$, which is dependent on the stoichiometry of the components. The diamide-imide equilibrium was studied in model reactions with NMR, and variable temperature infrared (IR) spectroscopy was used to investigate the temperature dependence of the equilibrium in the network. The temperature-dependent mechanical properties of the networks were found to be fully reversible, and the material could be reprocessed several times without loss of properties such as modulus or strain at break. The high processibility of these networks at elevated temperatures creates opportunities in additive manufacturing applications such as selective laser sintering.

\section{INTRODUCTION}

Dynamic covalent networks (DCNs) are polymer networks that combine the advantages of thermosets and thermoplastic polymers due to the presence of chemically reversible crosslinks. While DCNs possess typical features of thermosets, such as chemical resistance and dimensional stability, they may obtain thermoplastic characteristics under an external stimulus, ${ }^{1,2}$ such as heat ${ }^{1,3-5}$ or light, ${ }^{6-9}$ which allows them to be recycled and reprocessed. In the past decade, a large variety of reversible chemical reactions have been explored for the synthesis of DCNs, including cycloadditions, ${ }^{10-13}$ transesterification, ${ }^{4}$ transamination, ${ }^{14}$ olefin metathesis, ${ }^{15}$ disulfide exchange, ${ }^{16-18}$ thiol-thioester exchange, ${ }^{19}$ siloxane-silanol exchange, $^{20}$ imine-amine exchange, ${ }^{21}$ and other reactions. ${ }^{22}$

Many reversible reactions used in the synthesis of DCNs are associative in nature, ${ }^{22}$ and the resulting materials have been coined "vitrimers" because their temperature-dependent viscosity follows Arrhenius behavior, reminiscent of that of $\mathrm{SiO}_{2}$ glass. ${ }^{23}$ Because the cross-link density is constant, vitrimers generally are solvent resistant and retain structural integrity even at high temperatures.

In dissociative DCNs, the cross-link density decreases with temperature due to a shift of the equilibrium. Nevertheless, an Arrhenius relationship between viscosity and temperature exists when the fraction of dissociated functional groups remains small. ${ }^{24}$ If a significant fraction of exchangeable groups dissociates upon heating, the viscosity drops more strongly with temperature, following Williams-Landell-Ferry (WLF) behavior, similar to what is found for linear polymers around and above their glass transition temperature. ${ }^{25}$ Such dissociative networks offer the prospect of having a low-viscosity regime that facilitates melt processing, but excessive dissociation will give rise to undesirable flow. The challenge in these materials is to strike a balance between processibility and material integrity to provide a sufficiently wide processing window. $^{24,25}$

Recently, neighboring group participation has been introduced as a strategy to accelerate exchange reactions in DCNs. $^{26,27}$ Involvement of a functional group close to the exchanging moiety increases the reaction rate by providing a low free energy pathway to exchange via formation of a cyclic

Received: June 29, 2021

Revised: September 3, 2021

Published: October 13, 2021

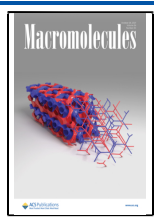


Scheme 1. (a) Diamide-imide Exchange Reaction and (b) Proposed Network Rearrangement Using the Diamide-imide Exchange Reaction as the Dynamic Motif

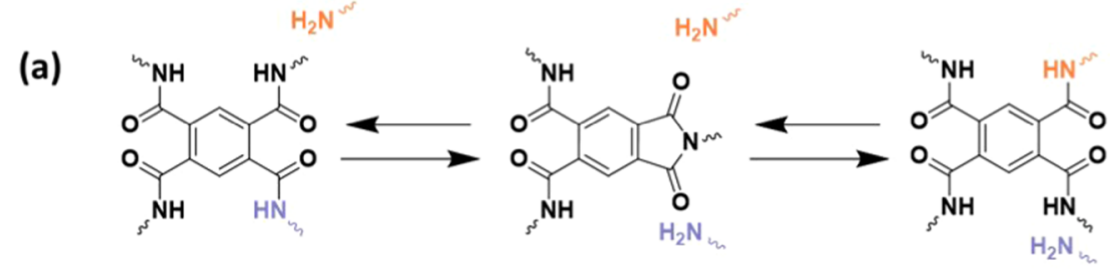

(b)

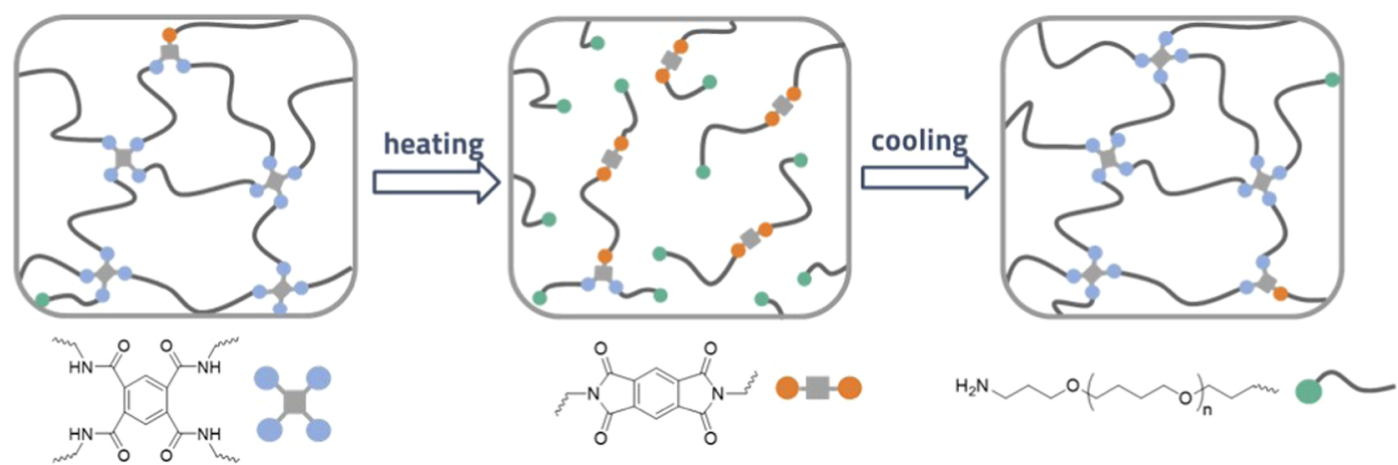

(a)
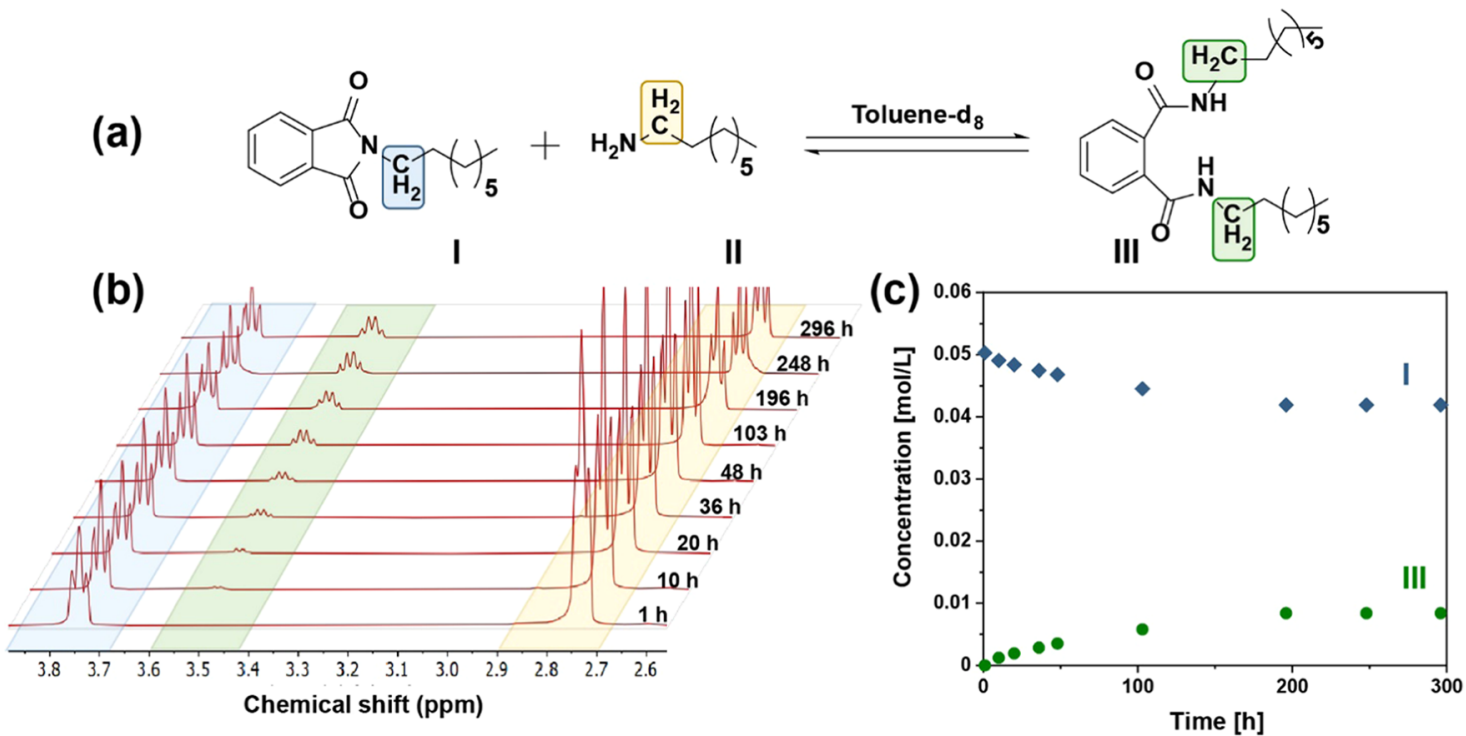

Figure 1. Model reaction of $N$-octylphthalimide (I) and octylamine (II) in toluene- $\mathrm{d}_{8}\left([\mathbf{I}]_{0}=0.0503 \mathrm{~mol} \cdot \mathrm{L}^{-1}\right.$ and $\left.[\mathbf{I I}]_{0}=0.1278 \mathrm{~mol} \cdot \mathrm{L}^{-1}\right)$. (a) Reaction scheme of the model reaction in which characteristic protons are highlighted. (b) ${ }^{1} \mathrm{H}$ NMR spectra of the model reaction mixture at $60{ }^{\circ} \mathrm{C}$ showing the evolutions of peak intensities of compounds I, II, and III as indicated in (a). (c) Concentrations over time of compounds I and III, determined from the peak intensities from the NMR spectra at $60^{\circ} \mathrm{C}$.

intermediate, a dissociative process. In their seminal work, $\mathrm{Du}$ Prez and co-workers showed a neighboring carboxylic acid group-participated transesterification of a phthalic acid derivative via a reactive anhydride intermediate. ${ }^{28}$ Faster transesterification in networks with neighboring group participation resulted in higher stress relaxation rates as compared to analogous networks without the ortho carboxylic acid group. Subsequently, our group incorporated an ortho sulfonic acid group as the neighboring group in aromatic polyesters, ${ }^{29}$ resulting in even faster relaxation and improved recyclability. Temperature-dependent relaxation showed Arrhenius behavior for these networks, which are therefore vitrimer-like. Arrhenius-like relaxation behavior was also reported in dissociative DCNs based on transamidation with neighboring group participation in an acetoacetyl-based amide. $^{30}$

Although the introduction of neighboring groups in these networks has led to faster dynamics, accessing the low-viscosity regime of dissociative networks also requires tuning thermodynamics. The equilibrium must be shifted to the cyclic intermediate to lower the cross-link density at high temperatures.

In the current work, we introduce DCNs based on transamidation via a relatively stable imide intermediate and we show that these networks combine substantial exchange rates at intermediate temperatures with a pronounced shift in the diamide-imide equilibrium that leads to network dissociation at high temperatures (Scheme 1). Facile reactions 
of phthalimides with alkylamines in the aminolysis of phthalimide $^{31}$ and the de-cross-linking of polyimides crosslinked with diamines at a high temperature under vacuum ${ }^{32}$ have been reported in the literature. These precedents encouraged us to explore the diamide-imide equilibrium, first in a small-molecule model reaction and then used in dynamic covalent networks formed from dianhydrides and diamines. The dynamic nature and flow properties of the networks are studied as a function of temperature.

\section{RESULTS AND DISCUSSION}

Model Reaction. To study the temperature dependence of the diamide-imide equilibrium, model reactions were performed using $N$-octylphthalimide (I) and octylamine (II) in toluene-d8 (Figure 1a) between 25 and $100{ }^{\circ} \mathrm{C}$. The progression of this reaction was monitored by ${ }^{1} \mathrm{H}$ NMR and the concentrations of I, II, and the product N1,N2dioctylphthalamide (III) were determined based on the integrals of the NMR peaks (Figure $1 \mathrm{~b}$ ). The reaction was considered to reach the equilibrium state once the concentrations of compounds remained constant over time. As shown in Figure 1c for a reaction temperature of $60{ }^{\circ} \mathrm{C}$, the concentration of I gradually decreased over time, while the concentration of III increased; after around $250 \mathrm{~h}$, the concentrations no longer changed.

Similar experiments as those shown in Figure 1 were carried out at several different temperatures between 25 and $100{ }^{\circ} \mathrm{C}$ and after achieving equilibrium, the equilibrium constants, $K$, were determined as

$$
K=\frac{[\mathrm{III}]}{[\mathrm{I}][\mathrm{II}]}
$$

and the results are summarized in Table 1.

Table 1. Equilibrium Concentrations and Equilibrium Constants of Model Compounds $\mathrm{N}$-Octylphthalimide (I), Octylamine (II), and N1,N2-Dioctylphthalamide (III) at Varying Temperatures

\begin{tabular}{rcccc}
$\begin{array}{r}\text { temp. } \\
\left({ }^{\circ} \mathrm{C}\right)\end{array}$ & $\begin{array}{c}{[\mathrm{I}]_{\mathrm{eq}}} \\
\left(\mathrm{mol} \cdot \mathrm{L}^{-1}\right)\end{array}$ & $\begin{array}{c}{[\mathrm{II}]_{\mathrm{eq}}} \\
\left(\mathrm{mol} \cdot \mathrm{L}^{-1}\right)\end{array}$ & $\begin{array}{c}{[\mathrm{III}]_{\mathrm{eq}}} \\
\left(\mathrm{mol} \cdot \mathrm{L}^{-1}\right)\end{array}$ & $\begin{array}{c}K \\
\left(\mathrm{~L}^{-1} \cdot \mathrm{mol}\right)\end{array}$ \\
25 & 0.0456 & 0.135 & 0.0122 & 1.98 \\
60 & 0.0419 & 0.119 & 0.0084 & 1.68 \\
80 & 0.0424 & 0.120 & 0.0079 & 1.55 \\
90 & 0.0426 & 0.120 & 0.0077 & 1.51 \\
100 & 0.0429 & 0.120 & 0.0074 & 1.43 \\
\hline
\end{tabular}

It is clear from these data that with increasing temperature, the equilibrium shifts toward the imide. The temperature dependence of this diamide-imide equilibrium was then further quantified by plotting the Van't Hoff curve (Figure 2) of the above model reaction. In toluene, the equilibrium constant $K$ decreases with increasing temperature from 1.99 at $25{ }^{\circ} \mathrm{C}$ to 1.43 at $100{ }^{\circ} \mathrm{C}$ and shifts toward the imide, which is in line with the literature. ${ }^{31,33}$ The standard reaction enthalpy $\left(\Delta H^{0}\right)$ and entropy $\left(\Delta S^{0}\right)$ were determined from the slope and intercept of the plot and resulted in $\Delta H^{0}=-3.7 \mathrm{~kJ} \cdot \mathrm{mol}^{-1}$ and $\Delta S^{0}=-6.6 \mathrm{~J} \cdot \mathrm{mol}^{-1} \cdot \mathrm{K}^{-1}$.

Synthesis of Dynamic Polyamide Networks. Based on the diamide-imide exchange reaction, a catalyst-free amideimide dynamic covalent network is designed and synthesized in three steps as shown in Scheme 2. In the first step, stoichiometric amounts of poly(tetrahydrofuran)-diamine

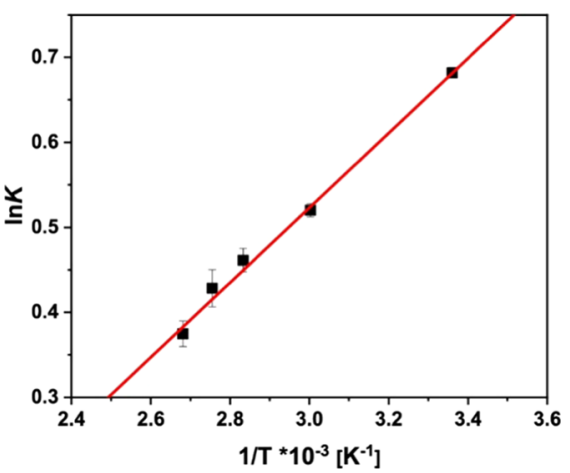

Figure 2. Van't Hoff plot of the model reaction of $N$-octylphthalimide (I) with octylamine (II) in toluene-d8 with $[\mathrm{I}]_{0}=0.0503 \mathrm{~mol} \cdot \mathrm{L}^{-1}$ and $[\mathrm{II}]_{0}=0.1278 \mathrm{~mol} \cdot \mathrm{L}^{-1}$.

(PTHF-diamine) and pyromellitic dianhydride (PDMA) were reacted in anhydrous tetrahydrofuran (THF) for 30 min at ambient temperature to form poly(amic acid)s. The FTIR spectrum of the product after removal of THF (see Supporting Information (SI) Figure S7) confirmed full conversion of anhydride to amic acid groups based on the disappearance of the anhydride bands at 1854 and $1775 \mathrm{~cm}^{-1}$. Subsequently, poly(amic acid) was dissolved in THF and refluxed at $66{ }^{\circ} \mathrm{C}$ overnight for imidization. After removal of the solvent, imidization was then completed by heating at 80 ${ }^{\circ} \mathrm{C}$ in vacuo for $15 \mathrm{~h}$. After drying, Fourier transform infrared (FTIR) spectroscopy was performed to verify formation of imide from the appearance of bands at 1780 and $1725 \mathrm{~cm}^{-1}$ (see SI Figure S7) ${ }^{34}$ and further confirmed by ${ }^{1} \mathrm{H}$ NMR spectra of poly(amic acid) and polyimide (see SI Figure S2). The number-average molar mass, $M_{n}$ of the linear polyimide was determined with size-exclusion chromatography in THF (see SI Figure S8) to be $20 \mathrm{~kg} \cdot \mathrm{mol}^{-1}$ relative to polystyrene standards. To this linear polyimide, various amounts of PTHFdiamine were added as cross-linker to form polyamide-imide networks, denoted as PTHF-PMDA- $X$, where $X$ represents the combined feeding ratio of diamine to dianhydride, with $X=1$ being the linear polyimide and $X=2$ being the network crosslinked with one additional equivalent of PTHF-diamine with respect to PMDA. Gel fractions of 84,82 , and $69 \%$ were determined with a hydrogen bond-breaking solvent mixture $\mathrm{MeOH}$ /THF for PTHF-PMDA-2, PTHF-PDMA-1.75, and PTHF-PMDA-1.5, respectively (see the SI for details).

Amide-Imide Exchange in the Network. The diamide-imide equilibrium in the PTHF-PMDA-2 network was investigated with variable-temperature infrared (VT-IR) spectroscopy by monitoring the intensities of the diamide and imide bands over a range of temperatures from 30 to $155^{\circ} \mathrm{C}$ at a heating rate of $1^{\circ} \mathrm{C} \cdot \mathrm{min}^{-1}$. The IR spectra in Figure 3a show the carbonyl bands of the imide at 1780 and $1725 \mathrm{~cm}^{-1}$, and of the diamide at 1630 and $1550 \mathrm{~cm}^{-1}$. The position of the diamide bands, as well as that of the $\mathrm{N}-\mathrm{H}$ stretch band at $3310 \mathrm{~cm}^{-1}$ (see SI Figure S9), indicates that the diamides are hydrogen bonded, probably leading to aggregation of the tetraamides in columnar stacks similar in structure to those found in tetraamide columnar liquid crystals ${ }^{35}$ or benzenetriamide thermoplastic elastomers. ${ }^{36}$ As shown in Figure $3 b$, the intensities of the diamide bands decrease, while for those of imide the bands increase upon heating. Above $140{ }^{\circ} \mathrm{C}$, the bands corresponding to the diamide groups almost disappear, indicating the dissociation of the network. Similarly, the 
Scheme 2. Three-Step Synthesis of the Polyamide Network

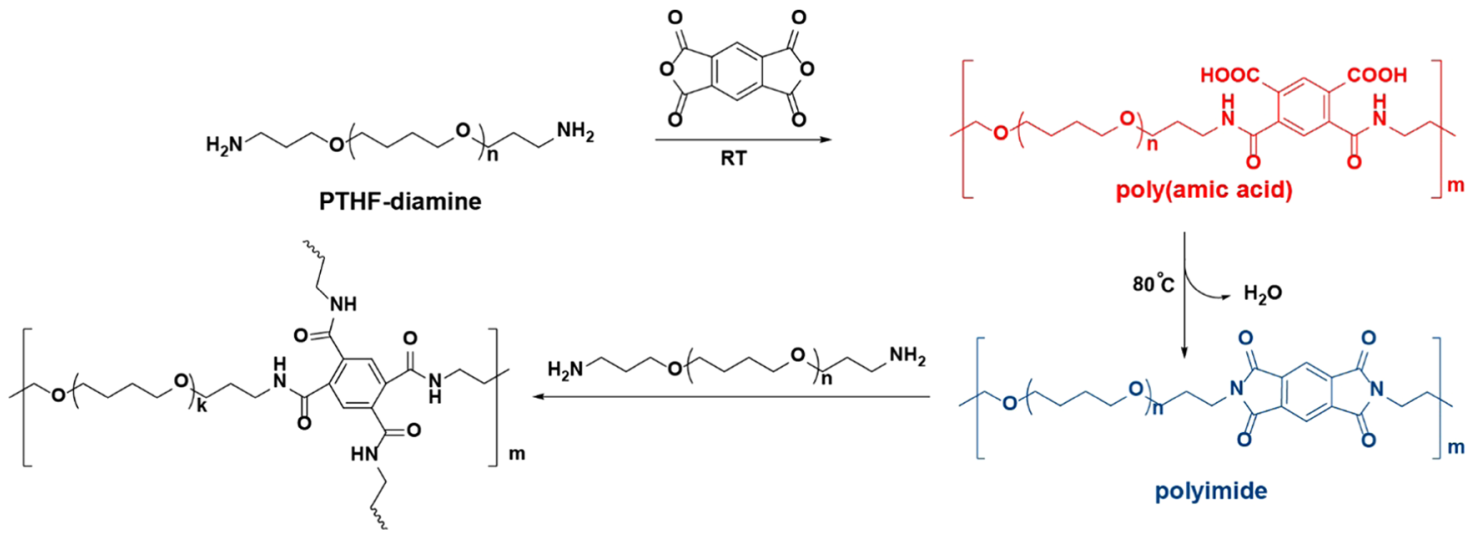

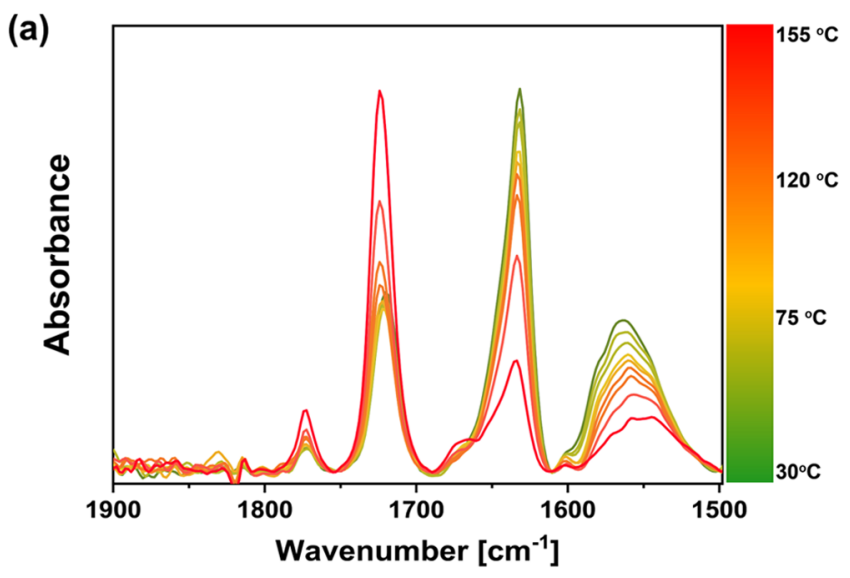

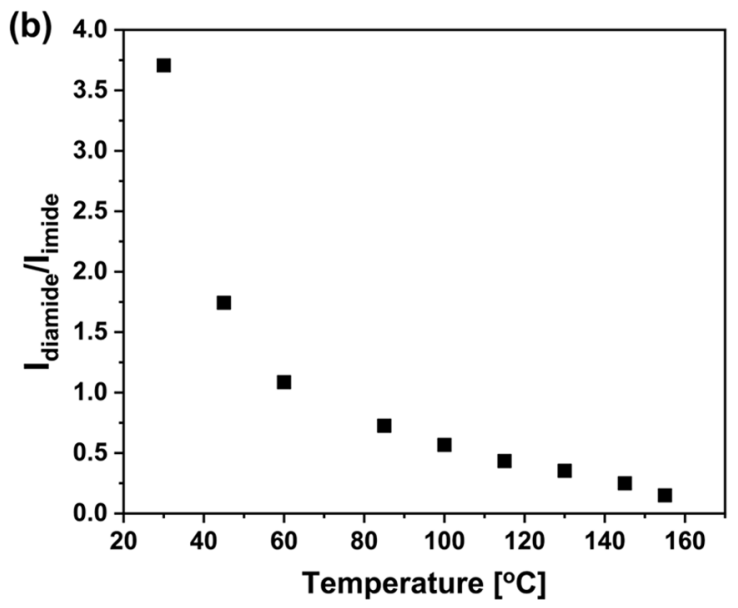

Figure 3. (a) Carbonyl region in VT-IR spectra of the PTHF-PMDA2 network upon heating at a rate of $1{ }^{\circ} \mathrm{C} \cdot \mathrm{min}^{-1}$ from 30 to $155{ }^{\circ} \mathrm{C}$ : the imide peak $\left(1725 \mathrm{~cm}^{-1}\right)$ increases and the diamide peaks $(1630$ and $1555 \mathrm{~cm}^{-1}$ ) decrease with increasing temperature. (b) Ratio between the intensities of diamide and imide peaks as a function of temperature.

reformation of the diamide bonds was studied by cooling the sample (see SI Figure S9). Analysis of the band intensities as a function of temperature gave a $K$ value that decreased from $\sim 5$ $\mathrm{M}^{-1}$ at $115{ }^{\circ} \mathrm{C}$ to 0.8 at $155^{\circ} \mathrm{C}$ (see SI Table S1).

(Thermo)Mechanical and Rheological Properties. Thermal properties of the networks were first studied by thermogravimetric analysis (TGA) and differential scanning calorimetry (DSC). Thermograms are shown in Figure 4.
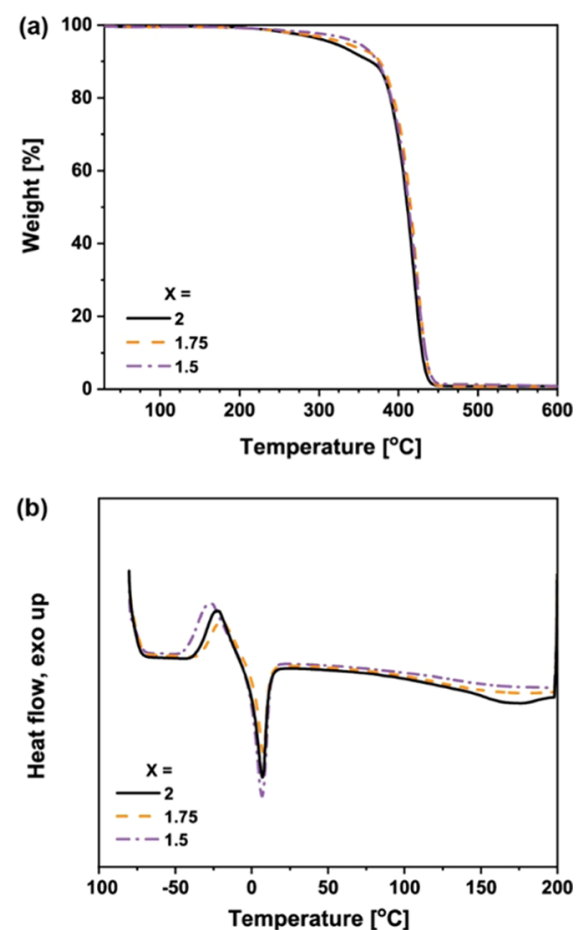

Figure 4. (a) TGA thermograms of the different PTHF-PMDA- $X$ networks obtained using a heating ramp from 30 to $600{ }^{\circ} \mathrm{C}$ at a rate of $10{ }^{\circ} \mathrm{C} \cdot \mathrm{min}^{-1}$ under $\mathrm{N}_{2}$ flow. (b) DSC thermograms of the second heating run traces of the different PTHF-PMDA- $X$ networks obtained at a ramping rate of $20^{\circ} \mathrm{C} \cdot \mathrm{min}^{-1}$. The networks presented are PTHFPMDA- $X$, with $X=2,1.75$, and 1.5 .

From the TGA results (Figure 4a), it can be concluded that the networks are stable up to $200{ }^{\circ} \mathrm{C}$ and have a degradation temperature $T_{\mathrm{d}, 5 \%} \geq 300{ }^{\circ} \mathrm{C}$. Furthermore, the networks contain (probably PTHF) crystalline regions below $0{ }^{\circ} \mathrm{C}$ as can be concluded from the cold crystallization and melting peaks in the DSC thermograms (Figure 4b).

To further characterize the (thermo)mechanical properties of the networks, dog-bone-shaped samples were prepared using a hot press at $125{ }^{\circ} \mathrm{C}$ for $30 \mathrm{~min}$ under a pressure of $100 \mathrm{bar}$ and studied with tensile testing and dynamic mechanical thermal analysis (DMTA). The results of these studies are shown in Figure 5.

Tensile tests were carried out in triplicate and representative stress-strain curves at room temperature are shown in Figure 5a (see the SI for more details). From these measurements, it 

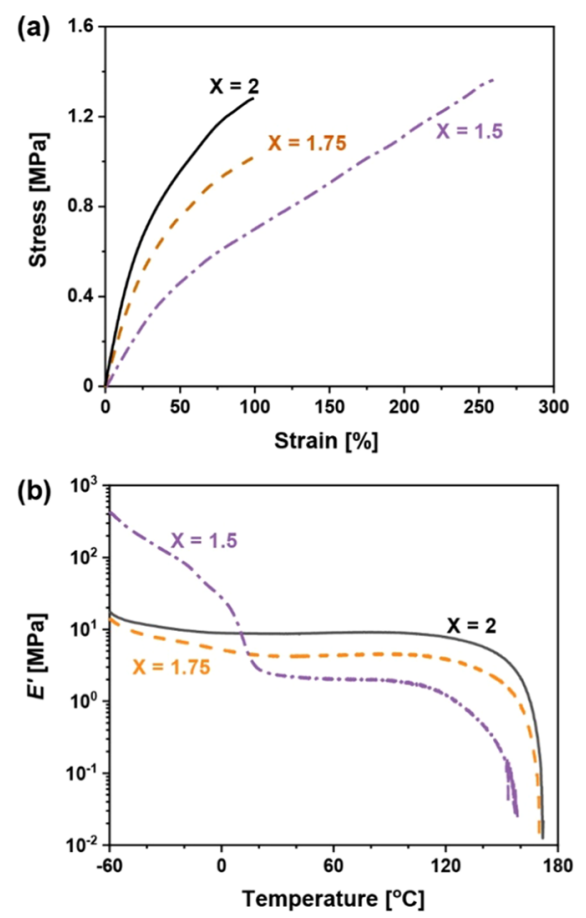

Figure 5. (a) Stress-strain curves of PTHF-PMDA- $X$ (with $X=2$, 1.75 , and 1.5) networks from tensile testing, obtained at room temperature using a strain rate of $30 \mathrm{~mm} \cdot \mathrm{min}^{-1}$. (b) Dynamic mechanical thermal analysis curves of the same networks, at a heating rate of $3{ }^{\circ} \mathrm{C} \cdot \mathrm{min}^{-1}$ from -60 to $180{ }^{\circ} \mathrm{C}$ and a frequency of $1 \mathrm{~Hz}$.

is clear that the Young's modulus increases with increasing amount of cross-linking diamine in PTHF-PMDA- $X: E \approx 1$ $\mathrm{MPa}$ for $X=1.5, E \approx 2 \mathrm{MPa}$ for $X=1.75$, and $E \approx 3 \mathrm{MPa}$ for $X$ $=2$. Furthermore, the material with the lowest amount of cross-linker, PTHF-PMDA-1.5, has a significantly higher elongation at break than the other two materials. Qualitatively, these results are expected as a higher cross-link density leads to stiffer materials. This is further confirmed by the DMTA results shown in Figure $5 \mathrm{~b}$, where the increasing storage modulus of the rubbery plateau with increasing $X$ is directly related to an increasing cross-link density. It is interesting to note that only the least cross-linked network showed a melting transition between -60 and $10{ }^{\circ} \mathrm{C}$, while PTHF-PMDA-1.75 and PTHF-PMDA-2 remain amorphous (see Figure $4 \mathrm{~b}$ ). The dog-bone-shaped samples after compression molding were all transparent; hence, the crystallinity of the PTHF-PMDA-1.5 network might stem from the cold crystallization of pendent (and/or free) PTHF chains during the conditioning step prior to DMTA measurements as shown in Figure $5 \mathrm{~b}$. At temperatures above $120{ }^{\circ} \mathrm{C}$, the storage modulus drops precipitously, indicative of the transition to viscous flow of the materials. Furthermore, there is a shift to higher temperatures for this transition with increasing cross-link density. It is clear that this viscous flow is related to the dynamic character of the dynamic covalent networks. We hypothesize that the abrupt transition is the combined (and possibly cooperative) effect of a shift in the diamide/imide equilibrium and dissociation of tetraamide stacks. Since the nature of the exchange reactions is dissociative, the observed flow may be accompanied by a greater (or even complete) disintegration of the network.

The dynamic nature of the polyamide-imide networks was further investigated using shear rheology with disk-shaped samples of $8 \mathrm{~mm}$ diameter and $1 \mathrm{~mm}$ thickness. The frequency-dependent shear moduli at varying temperature of the PTHF-PMDA-2 network are presented in Figure 6a. The
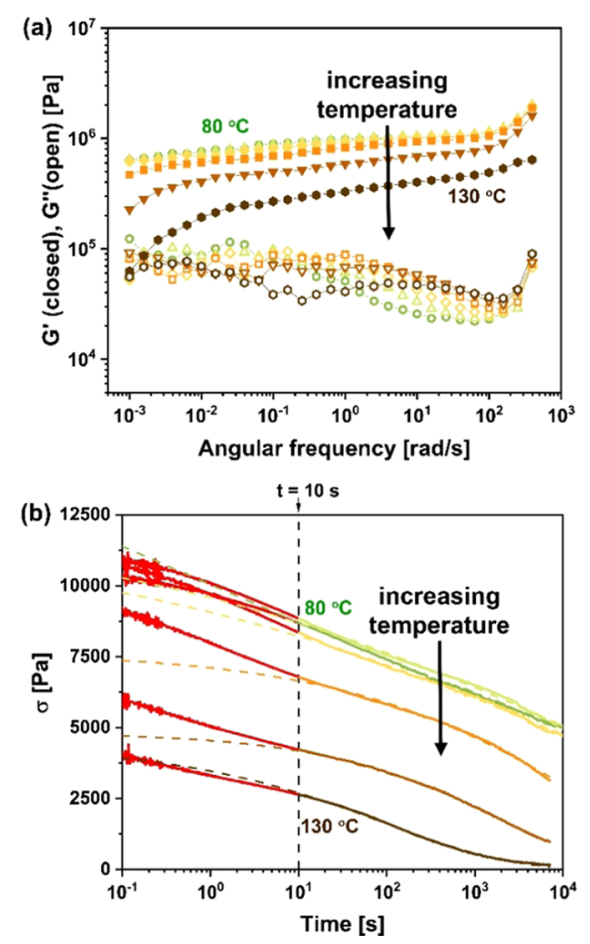

Figure 6. Shear rheology of the PTHF-PMDA-2 network at 80, 90, $100,110,120$, and $130{ }^{\circ} \mathrm{C}$. (a) Oscillatory frequency sweep measurement: $\omega=628$ to $10^{-3} \mathrm{rad} \cdot \mathrm{s}^{-1}$ at $0.1 \%$ strain. (b) Steptransient stress relaxation curves of the network at varying temperatures from 80 to $130{ }^{\circ} \mathrm{C}$; a step strain of $1 \%$ was applied. The dashed lines represent the stretched exponential fitting using eq 2.

significantly decreasing values for $G^{\prime}$ at higher frequencies for $T>120{ }^{\circ} \mathrm{C}$ are consistent with an increased, but not a complete, disintegration of the network at higher temperatures; if disintegration of the network were complete, a stronger frequency dependence of the moduli would be expected, as well as $G^{\prime \prime}>G^{\prime}$ at high frequencies. The oscillatory frequency sweep measurements further reveal the transient nature of the PTHF-PMDA network, evident by the significant drop of $G^{\prime}$ at lower frequencies $\left(<10^{-2} \mathrm{rad} \cdot \mathrm{s}^{-1}\right)$ for temperatures above and including $120^{\circ} \mathrm{C}$. At $130{ }^{\circ} \mathrm{C}$, PTHFPMDA-2 shows a crossover of $G^{\prime}$ and $G^{\prime \prime}$ at a frequency of $0.02 \mathrm{rad} \cdot \mathrm{s}^{-1}$. Similar results were obtained for PTHF-PMDA1.5 and PTHF-PMDA-1.75 (see the SI for more details).

Stress relaxation measurements of the PTHF-PMDA-2 network at temperatures between 80 and $130{ }^{\circ} \mathrm{C}$ are shown in Figure $6 \mathrm{~b}$. As the temperature decreases, the relaxation curves shift to longer time scales as the exchange reaction slows down and the equilibrium shifts toward diamide from imide, resulting in a higher cross-link density and less network mobility. The relaxation behavior cannot be adequately described by a Maxwell model (i.e., a single exponential decay), which describes relaxation in many of the reported dynamic covalent networks quite well. ${ }^{37-39}$ In a number of studies, ${ }^{40-43}$ a stretched exponential decay (eq 2) was used to describe the relaxation of the stress $\sigma(t)$, where the exponent $\beta$ is often considered as a factor taking into account the 
Table 2. Fit Parameters of Stress Relaxation Curves of PTHF-PMDA-X Networks Using Equation 2

\begin{tabular}{|c|c|c|c|c|c|c|c|c|c|}
\hline \multirow{2}{*}{$\frac{\text { network }}{\text { temp. }\left({ }^{\circ} \mathrm{C}\right)}$} & \multicolumn{3}{|c|}{$X=2$} & \multicolumn{3}{|c|}{$X=1.75$} & \multicolumn{3}{|c|}{$X=1.5$} \\
\hline & $\sigma_{0}(\mathrm{kPa})$ & $\beta$ & $\tau(\mathrm{s})$ & $\sigma_{0}(\mathrm{kPa})$ & $\beta$ & $\tau(\mathrm{s})$ & $\sigma_{0}(\mathrm{kPa})$ & $\beta$ & $\tau(\mathrm{s})$ \\
\hline 80 & 29 & 0.06 & 0.39 & 10 & 0.25 & $1.3 \times 10^{4}$ & 9.5 & 0.37 & $1.5 \times 10$ \\
\hline 90 & 13 & 0.13 & $2.1 \times 10^{4}$ & 9.6 & 0.27 & $9.3 \times 10^{3}$ & 9.4 & 0.39 & $9.7 \times 10$ \\
\hline 100 & 12 & 0.13 & $1.8 \times 10^{4}$ & 8.5 & 0.29 & $4.5 \times 10^{3}$ & 8.3 & 0.43 & $5.0 \times 10$ \\
\hline 110 & 7.7 & 0.27 & $1.3 \times 10^{4}$ & 6.6 & 0.34 & $2.0 \times 10^{3}$ & 6.1 & 0.48 & $2.1 \times 10$ \\
\hline 120 & 4.8 & 0.36 & $1.9 \times 10^{3}$ & 4.0 & 0.44 & $5.2 \times 10^{2}$ & 3.3 & 0.57 & $4.4 \times 10^{2}$ \\
\hline 130 & 4.4 & 0.31 & 98 & 1.8 & 0.44 & $1.3 \times 10^{2}$ & 1.8 & 0.58 & $1.1 \times 10^{2}$ \\
\hline
\end{tabular}

dispersity in a particular relaxation mode, with characteristic relaxation time $\tau^{44,45}$

$$
\sigma(t)=\sigma_{0} \exp \left\{-\left(\frac{t}{\tau}\right)^{\beta}\right\}
$$

Although it is not possible to fit the relaxation data using this model over the entire range of time, we nevertheless decided to use this relatively simple model to numerically characterize the stress relaxation behavior. Since our primary interest lies in network relaxation caused by transamidation characterized by longer relaxation times, data were fitted for $t \geq 10 \mathrm{~s}$ (see the SI for more details). The results of curve fitting using eq 2 are shown in Figure $6 \mathrm{~b}$ and the best-fit values of each parameter are summarized in Table 2. Adequate fits are obtained at longer times, but at most temperatures relaxation below $t=10$ $s$ is strongly underestimated, indicating that separate, faster relaxation modes are important at short time scales. These modes are more important at lower temperatures and are responsible for the aberrant fit results at $80{ }^{\circ} \mathrm{C}$, with an unrealistically low value of $0.39 \mathrm{~s}$ for $\tau$ in PTHF-PMDA-2. At this temperature, a large contribution of the faster modes around $t \approx 10 \mathrm{~s}$ overlaps strongly with relaxation through transamidation and obscures the dynamic covalent relaxation time. Above $80{ }^{\circ} \mathrm{C}$, the data follow the trends expected for a thermally activated chemical exchange in combination with a shift in the diamide-imide equilibrium to lower the cross-link density. Fitted relaxation times and the values of $\sigma_{0}$ continuously decrease with increasing temperatures, and the values of fitted $\sigma_{0}$ are close to the stresses observed in oscillatory shear rheology at a strain of $1 \%$ and $\omega=6.28 \mathrm{rad}$. $\mathrm{s}^{-1}$ (see SI Figure S23). The very low values for $\beta$, however, indicate a very high dispersity of relaxation times and suggests that relaxation at longer time scales is also a complex process that may involve dissociation of hydrogen-bonded aggregates in addition to the contribution from transamidation. A more detailed calculation of the retardation spectra is nontrivial, ${ }^{46}$ and is beyond the scope of the current study.

The creep response of the materials was investigated by applying a constant shear stress of $10 \mathrm{kPa}$ to the material for $1200 \mathrm{~s}$ at varying temperatures and monitoring the strain as a function of time. The results for PTHF-PMDA-2 are shown in Figure $7 \mathrm{a}$ (for the other two systems, see the SI). In all systems, below $110^{\circ} \mathrm{C}$, less than $3 \%$ strain is observed after the initial response, more than $90 \%$ of which is recovered after the release of stress. Above $110{ }^{\circ} \mathrm{C}$, the strain linearly increases with time after the initial response and the recovery drops to $29 \%$ of the deformation (see SI Figure S18 for creep recovery experiments). To compare the three materials better, the strain rates were determined from the strain-time curves for $200 \mathrm{~s}$ onward and are shown as a function of temperature in Figure $7 \mathrm{~b}$. The strain rates for all three networks increase drastically (a)
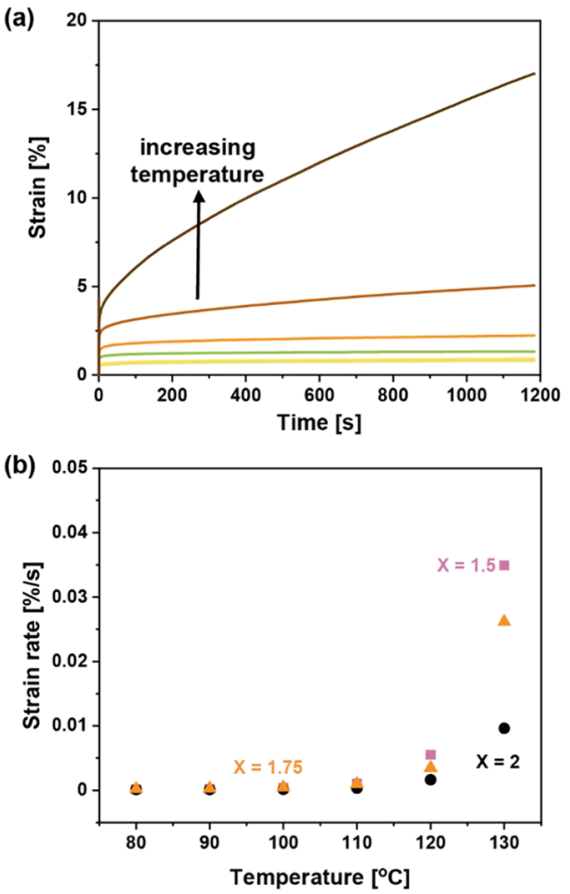

Figure 7. Shear rheology of PTHF-PMDA- $X$ networks at 80, 90, 100, 110,120 , and $130{ }^{\circ} \mathrm{C}$. (a) Creep results for PTHF-PMDA-2 at a constant stress of $10^{4} \mathrm{~Pa}$. (b) Comparison of strain rates (derived from the creep data acquired in (a) using $t>200 \mathrm{~s}$ ) for different PTHF-PMDA- $X$ networks (where $X=2,1.75,1.5$ ).

above $110{ }^{\circ} \mathrm{C}$ with a higher temperature dependence, evident from the steeper slope in Figure $7 \mathrm{~b}$. The temperature at which these changes occur corresponds to the transition to viscous flows as observed in the DMTA thermograms (Figure 5b).

Reprocessibility and Reversibility of Dynamic Poly(amide-imide) Networks. To confirm the reprocessibility of the dynamic poly(amide-imide) networks, the PTHFPMDA-2 samples were shredded and compression molded for three cycles. The stress-strain curves of the samples after each reprocessing cycle presented in Figure 8a show there is neither a significant loss in the Young's modulus nor in the elongation at break.

Furthermore, the reversibility of the network was studied using oscillatory shear rheology to heat and cool the sample for six cycles at a rate of $1{ }^{\circ} \mathrm{C} \cdot \mathrm{min}^{-1}$ and a strain of $1 \%$ and $\omega=$ $6.28 \mathrm{rad} \cdot \mathrm{s}^{-1}$. As can be seen from Figure $8 \mathrm{~b}$, the temperature dependences of the moduli remain the same, and despite some hysteresis in the reformation of the network upon cooling, the network fully restores if given sufficient time, allowing processing or reprocessing of the network without significant loss of mechanical properties. 

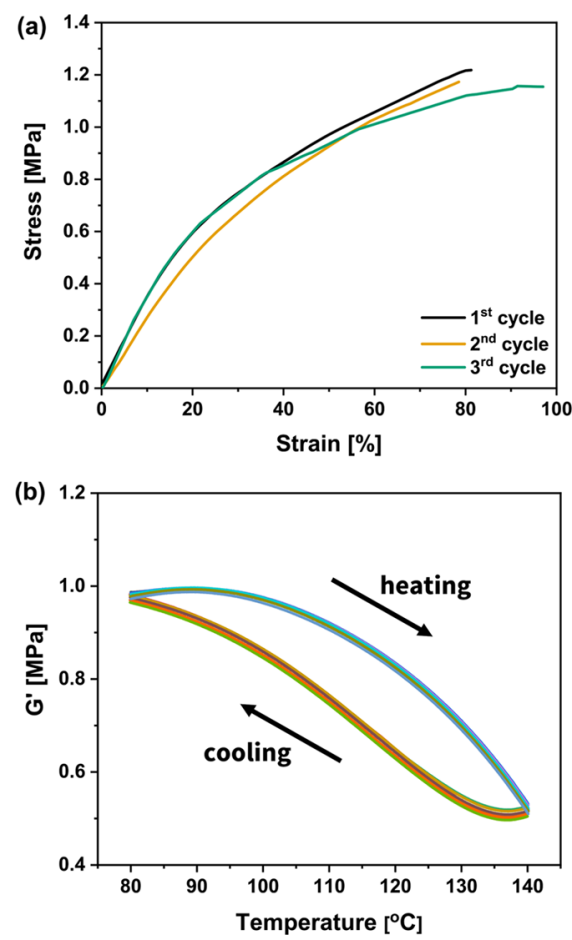

Figure 8. (a) Stress-strain curves of the PTHF-PMDA-2 network with three cycles of reprocessing by shredding and compression molding the samples acquired by tensile testing at a strain rate of 30 $\mathrm{mm} \cdot \mathrm{min}^{-1}$ at room temperature. (b) Reversibility of the network dissociation/reformation was studied using shear rheology for six cycles of heating and cooling from 80 to $140{ }^{\circ} \mathrm{C}$ at a rate of $1{ }^{\circ} \mathrm{C}$. $\min ^{-1}$ (strain of $1 \%$ and $\omega=6.28 \mathrm{rad} \cdot \mathrm{s}^{-1}$ ).

\section{CONCLUSIONS}

A novel type of dissociative dynamic covalent network has been synthesized by making use of the dynamic equilibrium between diamides and imides derived from pyromellitic dianhydride. Above $80{ }^{\circ} \mathrm{C}$, the networks show significant stress relaxation due to chemical exchange of amides via imide intermediates. The temperature dependence of the diamideimide equilibrium leads to a significant, but fully reversible reduction of cross-link density in the network above $110^{\circ} \mathrm{C}$. These features result in a moldable material with a strong drop in viscosity at high temperatures that aids its (re)processing. Probably as a result of extensive hydrogen bonding and aggregation of the tetraamide, viscosity loss is limited and material integrity is retained at intermediate temperatures.

We expect that the amide-imide chemistry demonstrated in this paper will find use in applications where temporarily reaching low viscosities is important, e.g., improving interfacial adhesion in additive manufacturing techniques such as fused filament fabrication.

\section{ASSOCIATED CONTENT}

\section{(s) Supporting Information}

The Supporting Information is available free of charge at https://pubs.acs.org/doi/10.1021/acs.macromol.1c01389.

Experimental details, characterization methods, and additional results of NMR studies, DSC, TGA, and rheology supporting data (PDF)

\section{AUTHOR INFORMATION}

\section{Corresponding Authors}

Johan P. A. Heuts - Department of Chemical Engineering \& Chemistry, Institute for Complex Molecular Systems, Eindhoven University of Technology, 5600 MB Eindhoven, The Netherlands; (1) orcid.org/0000-0002-9505-8242; Email: j.p.a.heuts@tue.nl

Rint P. Sijbesma - Department of Chemical Engineering \& Chemistry, Institute for Complex Molecular Systems, Eindhoven University of Technology, 5600 MB Eindhoven, The Netherlands; 이이.org/0000-0002-8975-636X; Email: r.p.sijbesma@tue.nl

\section{Authors}

Yinjun Chen - Department of Chemical Engineering \& Chemistry, Institute for Complex Molecular Systems, Eindhoven University of Technology, 5600 MB Eindhoven, The Netherlands

Huiyi Zhang - Department of Chemical Engineering \& Chemistry, Institute for Complex Molecular Systems, Eindhoven University of Technology, 5600 MB Eindhoven, The Netherlands

Soumabrata Majumdar - Department of Chemical Engineering \& Chemistry, Institute for Complex Molecular Systems, Eindhoven University of Technology, 5600 MB Eindhoven, The Netherlands

Rolf A.T.M. van Benthem - Department of Chemical Engineering \& Chemistry, Laboratory of Physical Chemistry, Eindhoven University of Technology, 5600 MB Eindhoven, The Netherlands; DSM Materials Science Center, 6167 RD Geleen, The Netherlands

Complete contact information is available at: https://pubs.acs.org/10.1021/acs.macromol.1c01389

\section{Author Contributions}

Y.C. and H.Z. contributed equally to this work. The manuscript was written through contributions of all authors.

\section{Funding}

This work was funded by the Dutch Research Council (NWO), Project No. 731.016.202.

\section{Notes}

The authors declare no competing financial interest.

\section{ACKNOWLEDGMENTS}

The authors gratefully acknowledge the Dutch Research Council (NWO) for funding this work (Project Number 731.016.202). Elisabeth Weyandt is thanked for the help with VT-IR measurements.

\section{REFERENCES}

(1) Adzima, B. J.; Kloxin, C. J.; Bowman, C. N. Externally Triggered Healing of a Thermoreversible Covalent Network via self-limited hysteresis heating. Adv. Mater. 2010, 22, 2784-2787.

(2) Kloxin, C. J.; Bowman, C. N. Covalent adaptable networks: smart, reconfigurable and responsive network systems. Chem. Soc. Rev. 2013, 42, 7161-7173.

(3) Stukenbroeker, T.; Wang, W.; Winne, J. M.; Du Prez, F. E.; Nicolä̈, R.; Leibler, L. Polydimethylsiloxane quenchable vitrimers. Polym. Chem. 2017, 8, 6590-6593.

(4) Montarnal, D.; Capelot, M.; Tournilhac, F.; Leibler, L. SilicaLike Malleable Materials from Permanent Organic Networks. Science 2011, 334, 965-968. 
(5) Chakma, P.; Konkolewicz, D. Dynamic Covalent Bonds in Polymeric Materials. Angew. Chem., Int. Ed. 2019, 58, 9682-9695.

(6) Worrell, B. T.; McBride, M. K.; Lyon, G. B.; Cox, L. M.; Wang, C.; Mavila, S.; Lim, C. H.; Coley, H. M.; Musgrave, C. B.; Ding, Y.; Bowman, C. N. Bistable and photoswitchable states of matter. Nat. Commun. 2018, 9, No. 2804.

(7) Zou, W.; Jin, B.; Wu, Y.; Song, H.; Luo, Y.; Huang, F.; Qian, J.; Zhao, Q.; Xie, T. Light-triggered topological programmability in a dynamic covalent polymer network. Sci. Adv. 2020, 6, No. eaaz2362.

(8) Miao, W.; Zou, W.; Jin, B.; Ni, C.; Zheng, N.; Zhao, Q.; Xie, T. On demand shape memory polymer via light regulated topological defects in a dynamic covalent network. Nat. Commun. 2020, 11, No. 4257.

(9) Houck, H. A.; Blasco, E.; Du Prez, F. E.; Barner-Kowollik, C. Light-Stabilized Dynamic Materials. J. Am. Chem. Soc. 2019, 141, 12329-12337.

(10) Chen, X.; Dam, M. A.; Ono, K.; Mal, A.; Shen, H.; Nutt, S. R.; Sheran, K.; Wudl, F. A Thermally Re-mendable Cross-Linked Polymeric Material. Science 2002, 295, 1698-1702.

(11) Billiet, S.; De Bruycker, K.; Driessen, F.; Goossens, H.; Van Speybroeck, V.; Winne, J. M.; Du Prez, F. E. Triazolinediones enable ultrafast and reversible click chemistry for the design of dynamic polymer systems. Nat. Chem. 2014, 6, 815-821.

(12) Sun, H.; Kabb, C. P.; Dai, Y.; Hill, M. R.; Ghiviriga, I.; Bapat, A. P.; Sumerlin, B. S. Macromolecular metamorphosis via stimulusinduced transformations of polymer architecture. Nat. Chem. 2017, 9, 817-823.

(13) Reutenauer, P.; Buhler, E.; Boul, P. J.; Candau, S. J.; Lehn, J.-M. Room Temperature Dynamic Polymers Based on Diels-Alder Chemistry. Chem. - Eur. J. 2009, 15, 1893-1900.

(14) Fox, C. H.; ter Hurrne, G. M.; Wojtecki, R. J.; Jones, G. O.; Horn, H. W.; Meijer, E. W.; Frank, C. W.; Hedrick, J. L.; García, J. M. Supramolecular motifs in dynamic covalent PEG-hemiaminal organogels. Nat. Commun. 2015, 6, No. 7417.

(15) Lu, Y.-X.; Tournilhac, F.; Leibler, L.; Guan, Z. Making Insoluble Polymer Networks Malleable via Olefin Metathesis. J. Am. Chem. Soc. 2012, 134, 8424-8427.

(16) Li, X.; Yu, R.; He, Y.; Zhang, Y.; Yang, X.; Zhao, X.; Huang, W. Self-Healing Polyurethane Elastomers Based on a Disulfide Bond by Digital Light Processing 3D Printing. ACS Macro Lett. 2019, 8, 15111516

(17) Amamoto, Y.; Otsuka, H.; Takahara, A.; Matyjaszewski, K. SelfHealing of Covalently Cross-Linked Polymers by Reshuffl ing Thiuram Disulfi de Moieties in Air under Visible Light. Adv. Mater. 2012, 24, 3975-3980.

(18) Fairbanks, B. D.; Singh, S. P.; Bowman, C. N.; Anseth, K. S. Photodegradable, Photoadaptable Hydrogels via Radical-Mediated Disulfide Fragmentation Reaction. Macromolecules 2011, 44, 24442450.

(19) Worrell, B. T.; Mavila, S.; Wang, C.; Kontour, T. M.; Lim, C.H.; McBride, M. K.; Musgrave, C. B.; Shoemaker, R.; Bowman, C. N. A user's guide to the thiol-thioester exchange in organic media: scope, limitations, and applications in material science. Polym. Chem. 2018, 9, 4523-4534.

(20) Zheng, P.; McCarthy, T. J. A Surprise from 1954 Siloxane Equilibration Is a Simple, Robust, and Obvious Polymer Self-Healing Mechanism. J. Am. Chem. Soc. 2012, 134, 2024-2027.

(21) Kathan, M.; Kovaricek, P.; Jurissek, C.; Senf, A.; Dallmann, A.; Thunemann, A. F.; Hecht, S. Control of Imine Exchange Kinetics with Photoswitches to Modulate Self-Healing in Polysiloxane Networks by Light Illumination. Angew. Chem., Int. Ed. 2016, 55, 13882-13886.

(22) Zou, W.; Dong, J.; Luo, Y.; Zhao, Q.; Xie, T. Dynamic Covalent Polymer Networks: from Old Chemistry to Modern Day Innovations. Adv. Mater. 2017, 29, No. 1606100.

(23) Guerre, M.; Taplan, C.; Winne, J. M.; Prez, F. E. D. Vitrimers: directing chemical reactivity to control material properties. Chem. Sci. 2020, 11, 4855-4870.
(24) Elling, B. R.; Dichtel, W. R. Reprocessable Cross-Linked Polymer Networks: Are Associative Exchange Mechanisms Desirable? ACS Cent. Sci. 2020, 6, 1488-1496.

(25) Jourdain, A.; Asbai, R.; Anaya, O.; Chehimi, M. M.; Drockenmuller, E.; Montarnal, D. Rheological Properties of Covalent Adaptable Networks with 1,2,3-Triazolium Cross-Links: The Missing Link between Vitrimers and Dissociative Networks. Macromolecules 2020, 53, 1884-1900.

(26) Van Lijsebetten, F.; Holloway, J. O.; Winne, J. M.; Du Prez, F. E. Internal catalysis for dynamic covalent chemistry applications and polymer science. Chem. Soc. Rev. 2020, 49, 8425-8438.

(27) Cuminet, F.; Caillol, S.; Dantras, É.; Leclerc, É.; Ladmiral, V. Neighboring Group Participation and Internal Catalysis Effects on Exchangeable Covalent Bonds: Application to the Thriving Field of Vitrimer Chemistry. Macromolecules 2021, 54, 3927-3961.

(28) Delahaye, M.; Winne, J. M.; Du Prez, F. E. Internal Catalysis in Covalent Adaptable Networks: Phthalate Monoester Transesterification As a Versatile Dynamic Cross-Linking Chemistry. J. Am. Chem. Soc. 2019, 141, 15277-15287.

(29) Zhang, H.; Majumdar, S.; van Benthem, R. A. T. M.; Sijbesma, R. P.; Heuts, J. P. A. Intramolecularly Catalyzed Dynamic Polyester Networks Using Neighboring Carboxylic and Sulfonic Acid Groups. ACS Macro Lett. 2020, 9, 272-277.

(30) Liu, Z.; Yu, C.; Zhang, C.; Shi, Z.; Yin, J. Revisiting Acetoacetyl Chemistry to Build Malleable Cross-Linked Polymer Networks via Transamidation. ACS Macro Lett. 2019, 8, 233-238.

(31) Wolfe, S.; Hasa, S. K. Five-membered rings. 11.' Inter and intramolecular reactions of simple amines with $\mathrm{N}$-substituted phthalimides. Methylamine as a reagent for removal of a phthaloyl group from nitrogen. Can. J. Chem. 1970, 48, 3572-3579.

(32) Liu, Y.; Wang, R.; Chung, T.-S. Chemical cross-linking modification of polyimide membranes for gas separation. J. Membr. Sci. 2001, 189, 231-239.

(33) López-Badillo, M.; Velasco-Hernández, M. A.; García-Castro, M. A.; Aranda-García, R. J.; Galicia-Aguilar, J. A.; Guevara-Espinosa, M. D.; Carreón-Rodríguez, V. E. Obtaining kinetic parameters of polyamide imide reaction. Rev. Mex. Ing. Quim. 2019, 19, 783-791.

(34) Ahmadi, M.; Rad-Moghadam, K.; Hatami, M. Investigation of morphological aspects and thermal properties of $\mathrm{ZnO} /$ poly(amideimide) nanocomposites based on levodopa-mediated diacid monomer. Polym. Bull. 2019, 76, 53-72.

(35) Shishido, Y.; Anetai, H.; Takeda, T.; Hoshino, N.; Noro, S.-i.; Nakamura, T.; Akutagawa, T. Molecular Assembly and Ferroelectric Response of Benzenecarboxamides Bearing Multiple -CONHC14H29 Chains. J. Phys. Chem. C 2014, 118, 21204-21214.

(36) Roosma, J.; Mes, T.; Leclère, P.; Palmans, A. R. A.; Meijer, E. W. Supramolecular Materials from Benzene-1,3,5-tricarboxamideBased Nanorods. J. Am. Chem. Soc. 2008, 130, 1120-1121.

(37) Denissen, W.; Rivero, G.; Nicolaÿ, R.; Leibler, L.; Winne, J. M.; $\mathrm{Du}$ Prez, F. E. Vinylogous Urethane Vitrimers. Adv. Funct. Mater. 2015, 25, 2451-2457.

(38) El-Zaatari, B. M.; Ishibashi, J. S. A.; Kalow, J. A. Cross-linker control of vitrimer flow. Polym. Chem. 2020, 11, 5339-5345.

(39) Zhou, Y.; Goossens, J. G.; Sijbesma, R. P.; Heuts, J. P. Poly (butylene terephthalate)/glycerol-based vitrimers via solid-state polymerization. Macromolecules 2017, 50, 6742-6751.

(40) Li, L.; Chen, X.; Jin, K.; Torkelson, J. M. Vitrimers Designed Both To Strongly Suppress Creep and To Recover Original CrossLink Density after Reprocessing: Quantitative Theory and Experiments. Macromolecules 2018, 51, 5537-5546.

(41) Lessard, J. J.; Scheutz, G. M.; Hughes, R. W.; Sumerlin, B. S. Polystyrene-Based Vitrimers: Inexpensive and Recyclable Thermosets. ACS Appl. Polym. Mater. 2020, 2, 3044-3048.

(42) Self, J. L.; Dolinski, N. D.; Zayas, M. S.; Read de Alaniz, J.; Bates, C. M. Brønsted-Acid-Catalyzed Exchange in Polyester Dynamic Covalent Networks. ACS Macro Lett. 2018, 7, 817-821.

(43) Majumdar, S.; Zhang, H.; Soleimani, M.; van Benthem, R. A. T. M.; Heuts, J. P. A.; Sijbesma, R. P. Phosphate Triester Dynamic Covalent Networks. ACS Macro Lett. 2020, 9, 1753-1758. 
(44) Fancey, K. S. A mechanical model for creep, recovery and stress relaxation in polymeric materials. J. Mater. Sci. 2005, 40, 4827-4831.

(45) Williams, G.; Watts, D. C. Non-symmetrical dielectric relaxation behaviour arising from a simple empirical decay function. Trans. Faraday Soc. 1970, 66, 80-85.

(46) Ferry, J. D. Viscoelastic Properties of Polymers; John Wiley \& Sons, 1980; p 672. 